\title{
COVID-19 Infection in An HIV-Positive Patient
}

\author{
Caskurlu H., and Cag Y.
}

\section{ABSTRACT}

\begin{abstract}
The COVID-19 pandemic affects all age groups but follows a more mortal trajectory in patients with preexisting conditions such as immune deficiency, chronic lung disease, diabetes, and cardiovascular problems. Hence, HIV-positive patients with immune deficiency are at risk, therefore, these patients need to have continuous access to treatment during the pandemic. The number of defined COVID-19 positive HIV patients is very limited even though there are approximately $\mathbf{3 7 . 9}$ million HIV-positive patients globally. Therefore, we decided to publish this study reporting an HIV patient treated for COVID-19 in our clinic.
\end{abstract}

Keywords: COVID 19, HIV, pandemic, case report

\author{
Published Online: February 2, 2021 \\ ISSN: $2736-5476$ \\ DOI : $10.24018 /$ clinicmed.2021.2.1.14

\section{Caskurlu H.*} \\ İstanbul Medeniyet University Medical \\ Faculty Department of Infectious \\ Diseases,İstanbul,Turkey \\ Cag Y. \\ İstanbul Medeniyet University Medical \\ Faculty Department of Infectious \\ Diseases, İstanbul,Turkey \\ *Corresponding Author
}

\section{INTRODUCTION}

New type coronavirus SARS COV-2 first surfaced in the Chinese city of Wuhan on December 1st, 2019, to turn into a global concern in quick succession. The World Health Organization declared this a pandemic on March 11, 2020. The patients infected with COVID-19 have $80 \%$ mild symptoms, while $14 \%$ become serious and $6 \%$ attain critical conditions. Patients with pneumonia due to COVID-19 require hospital admission $10 \%$ of the time, while $10 \%$ within this group develop an acute respiratory distress syndrome (ARDS) subject to intensive care unit admission [1], [2].

While COVID-19 mortality rates are higher among elderly patients with chronic lung disease, diabetes, and cardiovascular diseases, it is also known to cause multiorgan deficiencies and death among younger patients [3]. COVID19 also poses a significant burden for patients living with HIV [4].

There are currently no specific treatments for COVID-19 with proven results and efficacy. Over 100 randomized studies involving various medications are currently ongoing to find a cure for this disease. These medications include antiretrovirals used in HIV treatment as well [1], [5].

The number of defined COVID-19 positive HIV patients is very limited even though there are approximately 37.9 million HIV-positive patients globally. Therefore, we deemed important to publish this study reporting an HIV patient that has been treated for COVID-19 in our clinic.

\section{CASE}

A 44-year old man was admitted to our hospital emergency room (ER) with fever and cough symptoms. It was discovered that even though the patient took Lopinavir/Ritonavir and Emtricitabine-Tenofovir disoproxil antiretroviral treatment due to acquired immune deficiency syndrome (AIDS) for the past 5 years, he had stopped taking medications in the past month. The patient had been suffering symptoms for the past 10 days and had been prescribed oseltamivir by the previous medical center, without any improvement to his general condition. On physical examination, his fever has 37.9 degree, turgor, normal tonus, bilaterally equal breath, and no ral-ronkus were detected. No anomalies were found in the cardiovascular, gastrointestinal, and genitourinary systems. Blood pressure was recorded at $120 / 80 \mathrm{mmHg}$, pulse rate was $80 / \mathrm{min}$, and breath rate was $18 / \mathrm{min}$. The patient was transferred to the infectious diseases ward following discovery of bilateral peripheral infusion in the thorax CT performed at the ER (Fig. 1). Nasopharyngeal swab test was found positive for SARS-CoV-2 by reverse transcription PCR assay. Initial treatment was lopinavir/ritonavir 400/100 mg/d, Doxycycline 2x100mg/d, Ceftriaxone 2x1 g/d iv, Emtricitabine/Tenofovir disoproxil 200/245 mg 1x1/d. HIV RNA PCR results taken during admission returned to 90 $\mathrm{IU} / \mathrm{ml}$, with aCD4 count of $623 / \mathrm{mm}^{3}$. The patient was discharged with directions of self-isolation after 5 days of hospitalization following his improvement in general condition and stable vital functions. 


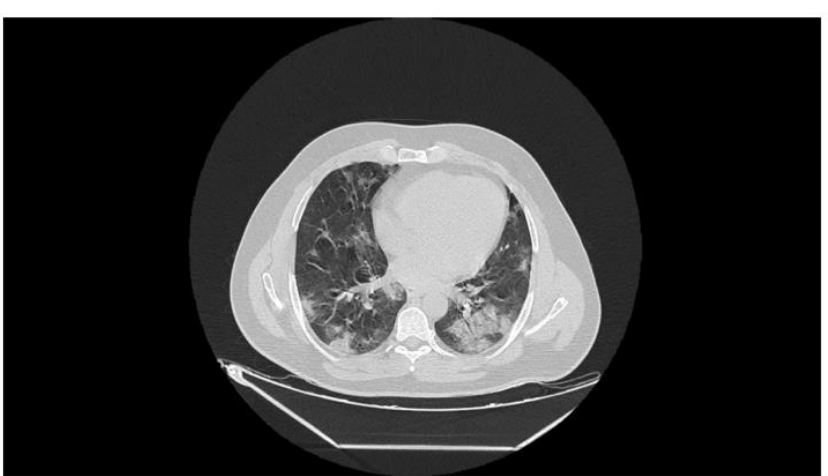

Fig. 1: Patient's Thorax CT

\section{CONCLUSION}

While COVID-19 impacts everyone, it is evident that mortality rates are higher among patients with comorbidities and immune deficiencies. Hence, it is especially important to evaluate patients with acquired immune deficiencies [4]. During the pandemic in April, 5 patients were reported in Spain and 1 in Wuhan, China, with co-infections of HIV and COVID-19 [6,7]. Most recently by May 18, the amount of case reports has reached a dozen, covering approximately 100 COVID-19 infected HIV patients [8]. Our case is different from these others since the patient was discharged without intensive care unit intervention. Age younger than 50 years, no preexisting conditions such as hypertension and/or diabetes, having no respiratory issues during admission, and having a CD4 number of $623 / \mathrm{mm}^{3}$ are all important factors leading to patient's improvement and discharge.

\section{REFERENCES}

[1] Infectious Diseases Society of American Guidelines on the Treatment and Management of Patients with COVID-19 [Internet]. [cited $2020 \mathrm{Jul}$ 13]. Available from: https://www.idsociety.org/practiceguideline/covid-19-guideline-treatment-and-management/

[2] COVID-19 Rehberi [Internet]. [cited 2020 Jul 13]. Available from: https://covid19bilgi.saglik.gov.tr./tr/covid-19-rehberi.html C. Y. Lin, M. Wu, J. A. Bloom, I. J. Cox, and M. Miller, "Rotation, scale, and translation resilient public watermarking for images," IEEE Trans. Image Process., vol. 10, no. 5, pp. 767-782, May 2001.

[3] Islam M. S., Sobur M. A , Akter M., Nazmul K. H. M, Nazir H., Toniolo A., et al. Coronavirus Disease 2019 (COVID-19) pandemic, lessons to be learned! J Adv Vet Anim Res [Internet]. 2020 [cited 2020 Jul 13];7(2):260-80. Available from: http://bdvets.org/javar/http://doi.org/10.5455/javar.2020.g418W.-K.

Chen, Linear Networks and Systems, Belmont, CA: Wadsworth, 1993, pp. 123-135.

[4] Shiau S., Krause K. D., Valera P., Swaminathan S., Halkitis P. N., The Burden of COVID-19 in People Livingwith HIV: A Syndemic Perspective [Internet]. Vol. 1, AIDS and Behav. Springer; 2020 [cited 2020 Jul 13]. p. 1. Available from: /pmc/articles/PMC7165075/?report=abstract

[5] Sanders J. M., Monogue M. L., Jodlowski T. Z., Cutrell J. B., Pharmacologic Treatments for Coronavirus Disease 2019 (COVID-19): A Review [Internet]. Vol. 323, JAMA; 2020 [cited 2020 Jul 13]. p. 1824-36. Availablefrom: https://pubmed.ncbi.nlm.nih.gov/32282022/

[6] Zhu F., Cao Y., Xu S., Zhou M., Co-infection of SARS-CoV-2 and HIV in a patient in Wuhan city, China. J MedVirol [Internet]. John Wiley and Sons Inc.; 2020 Jun 11 [cited 2020 Jul 13];92(6):529-30. Available from: https://onlinelibrary.wiley.com/doi/abs/10.1002/jmv.25732
[7] Blanco J. L., Ambrosioni J., Garcia F., Martínez E., Soriano A. Mallolas J., et al. COVID-19 in patients with HIV: clinical case series [Internet]. Vol. 7, The Lancet HIV. Elsevier Ltd; 2020 [cited 2020 Jul 13]. p. e314-6. Available from: https://pubmed.ncbi.nlm.nih.gov/32304642/

[8] Härter G., Spinner C. D., Roider J., Bickel M., Krznaric I., Grunwald S., et al. COVID-19 in people living with human immuno deficiency virus: a case series of 33 patients. Infection [Internet]. Springer; 2020 [cited 2020 Jul 13]; 14:1. Available from: /pmc/articles/PMC7211976/?report=abstr

Hülya Çaşkurlu, Educational background: Graduated from Istanbul School of Medicine at 1985

Cerrahpasa Medical School, Department of Clinical Microbiology and Infectious Diseases, 1992

An observer at MD Anderson Cancer Center, Houston, Texas, 1990 Istanbul Medeniyet University, School of Medicine, Department of Infectious Diseases, 2015-present.

Academic Disciplines and Expertise: Infectious disease, antimicrobialresistant, Hepatitis B, HIV, vaccine. 